\title{
Revista Española de Investigaciones Sociológicas
}

Revista Española

de Investigaciones Sociológicas

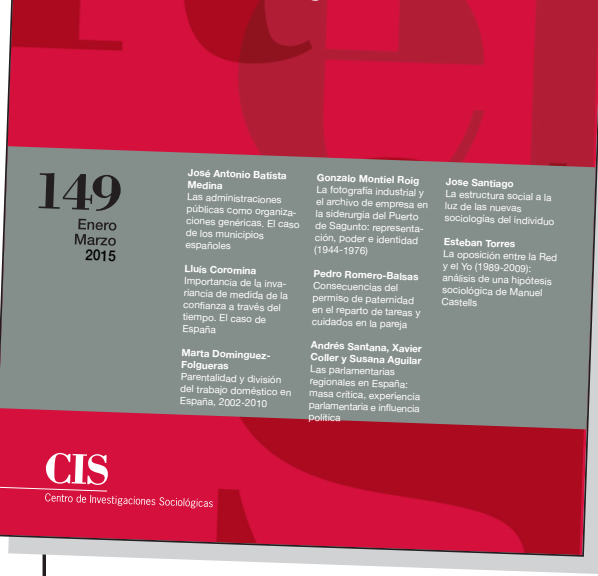

Director

Félix Requena Santos

Secretaria

$M^{\mathrm{a}}$ Paz Cristina Rodríguez Vela

Consejo Editorial

Inés Alberdi Alonso, Miguel Caínzos López, Teresa Castro Martín, Elisa Chuliá Rodrigo, José Ramón Flecha García, Luis Garrido Medina, Rafael Gobernado Arribas, Rodolfo Gutiérrez Palacios, Amparo Lasén Díaz, Francisco Llera Ramo, Pablo Oñate Rubalcaba, Carlota Solé i Puig, Benjamín Tejerina Montaña, Cristobal Torres Albero

\section{Edita}

Centro de Investigaciones Sociológicas (CIS) Montalbán, 8. 28014 Madrid

www.cis.es - E-mail: publicaciones@cis.es

Precios

Suscripción anual (4 números)

- Electrónica:
Instituciones
$160 €$
Particulares $50 €$

- En papel y electrónica:

\begin{tabular}{lcc} 
& España & $\begin{array}{c}\text { Resto } \\
\text { del mundo }\end{array}$ \\
\cline { 2 - 3 } Instituciones & $180 €$ & $220 €$ \\
Particulares & $60 €$ & $100 €$
\end{tabular}

- Compra de números sueltos en papel:

Cada número $20 €$

\section{CIS}

Centro de Investigaciones Sociológicas www.reis.cis.es reis.metapress.com

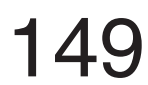

Enero-Marzo 2015
José Antonio Batista Medina

Las administraciones públicas como organizaciones genéricas. El caso de los municipios españoles

\section{Lluís Coromina} Importancia de la invariancia de medida de la confianza a través del tiempo. El caso de España

\section{Marta Dominguez- Folgueras}

Parentalidad y división del trabajo doméstico en España, 2002-2010

\section{Gonzalo Montiel Roig}

La fotografía industrial y el archivo de empresa en la siderurgia del Puerto de Sagunto: representación, poder e identidad (1944-1976)

\section{Pedro Romero-Balsas}

Consecuencias del permiso de paternidad en el reparto de tareas y cuidados en la pareja

Andrés Santana, Xavier Coller y Susana Aguilar Las parlamentarias regionales en España: masa crítica, experiencia parlamentaria e influencia política

\section{Jose Santiago}

La estructura social a la luz de las nuevas sociologías del individuo

\section{Esteban Torres}

La oposición entre la Red y el Yo (1989-2009): análisis de una hipótesis sociológica de Manuel Castells

\section{Solicitudes de suscripción}

EBSCO Subscription Services España, S. L.

Avda. Bruselas, 7. 28109 Alcobendas (Madrid)

Tel.: 914902502 - Fax: 914902325

E-mail: ndiaz@ebsco.es - www.ebsco.com

Metapress

E-mail: support@metapress.com reis.metapress.com 